\title{
Association of exposure to Toxoplasma gondii, Epstein-Barr Virus, Herpes Simplex virus Type 1 and Cytomegalovirus with new-onset depressive and anxiety disorders: An 11-year follow-up study
}

\section{Markkula, Niina}

2020-07

Markkula , N , Lindgren , M , Yolken, R H \& Suvisaari , J 2020 , ' Association of exposure to Toxoplasma gondii, Epstein-Barr Virus, Herpes Simplex virus Type 1 and Cytomegalovirus with new-onset depressive and anxiety disorders: An 11-year follow-up study ' , Brain, Behavior, and Immunity, vol. 87 , pp. 238-242 . https://doi.org/10.1016/j.bbi.2019.12.001

http://hdl.handle.net/10138/322331

https://doi.org/10.1016/j.bbi.2019.12.001

acceptedVersion

Downloaded from Helda, University of Helsinki institutional repository.

This is an electronic reprint of the original article.

This reprint may differ from the original in pagination and typographic detail.

Please cite the original version. 


\title{
Association of exposure to Toxoplasma gondii, Epstein-Barr Virus, Herpes Simplex virus Type 1 and Cytomegalovirus with new-onset depressive and anxiety disorders: An 11-year follow-up study
}

\author{
Niina Markkula ${ }^{\mathrm{a}, \mathrm{b}, *}$, Maija Lindgren ${ }^{\mathrm{c}}$, Robert H. Yolken ${ }^{\mathrm{d}}$, Jaana Suvisaari ${ }^{\mathrm{b}}$ \\ ${ }^{a}$ Department of Psychiatry, Helsinki University and Helsinki University Hospital, Helsinki, Finland \\ ${ }^{\mathrm{b}}$ Faculty of Medicine Clinica Alemana, Universidad del Desarrollo, Santiago, Chile \\ ${ }^{\mathrm{c}}$ Mental Health Unit, Finnish Institute for Health and Welfare, Helsinki, Finland \\ ${ }^{\mathrm{d}}$ Stanley Division of Developmental Neurovirology, Department of Pediatrics, John Hopkins University School of Medicine, Baltimore, MD, USA
}

\section{A B S T R A C T}

Background: Some prevalent infections have been associated with common mental disorders, but there are few longitudinal studies, and results are inconsistent. We aimed to assess whether serological evidence of exposure to Toxoplasma gondii (T. gondii), Epstein-Barr Virus (EBV), Herpes Simplex virus Type 1 (HSV-1) and Cytomegalovirus (CMV) predict development of new-onset depressive and anxiety disorders.

Methods: In a nationally representative sample of the Finnish adult population aged 30 and over (BRIF8901, $\mathrm{n}=8028$ ), IgG antibodies for T. gondii, EBV, HSV-1 and CMV were measured in plasma samples. The population was followed up for 11 years and new-onset depressive and anxiety disorders were diagnosed with the Composite International Diagnostic Interview. Associations were analysed controlling for sex, age, educational level, region of residence and marital status, and in separate analyses also for C-reactive protein level.

Results: Seropositivity and serointensity of the four infectious agents were not associated with an increased risk of new-onset depressive or anxiety disorders. Seropositivity for CMV at baseline was associated with a lower risk of new-onset generalized anxiety disorder (adjusted OR 0.43, 95\% CI 0.22-0.86 for CMV positive persons).

Conclusion: The results of this large, nationally representative longitudinal study suggest that common viral infections are not significant risk factors for common mental disorders. The association of CMV with a lower risk of generalized anxiety disorder warrants further investigation.

\section{Introduction}

In the quest for defining etiological mechanisms for common mental disorders, infections have been identified as a potential risk factor (Benros et al., 2013; Burgdorf et al., 2019). Infections may cause psychiatric symptoms via several mechanisms, for example cytokine signaling, perturbation of the tryptophan metabolism and activation of the hypothalamus-pituitary-adrenal axis (Dantzer et al., 2008). Specifically, anxiety and depression have been associated with several viral infections (Coughlin, 2012). In a recent meta-analysis, most infectious agents were not significantly associated with depression, but herpes simplex virus-1 (HSV-1), Epstein-Barr virus (EBV), varicella zoster virus, Chlamydophila trachomatis and Borna disease virus showed a significant association (Wang et al., 2014).

Toxoplasma gondii (T. gondii) is an intracellular parasite that infects one third of the world's population (Saadatnia and Golkar, 2012). The prevalence in the Finnish population is approximately 20\% (Suvisaari et al., 2017). Intrauterine infection may be fatal or severely affect the fetus. In adults, it normally causes an asymptomatic primary infection, but may become latent and reactivate later in life. Recent meta-analyses have found associations between $T$. gondii infection and schizophrenia, bipolar disorder, obsessive-compulsive disorder and addiction, but not depression (Nayeri Chegeni et al., 2019; Sutterland et al., 2015). In the Finnish population, toxoplasma seropositivity was associated with psychotic-like symptoms (Lindgren et al., 2018), generalized anxiety disorder (GAD), depressive symptoms and comorbid depressive and anxiety disorders in a cross-sectional study (Suvisaari et al., 2017). In other prior cross-sectional studies, toxoplasma seropositivity has been associated with GAD (Markovitz et al., 2015). T. gondii and cytomegalovirus (CMV) seropositivity have also been associated with a history of suicide attempts (Dickerson et al., 2017).

CMV, also known as human herpesvirus-5 (HHV-5) and EBV are common viruses that generally cause asymptomatic or mild primary infections and form a lifelong latent infection. The prevalence rates of CMV and EBV seropositivity in the Finnish adult population are $84 \%$ and 98\%, respectively (Torniainen-Holm et al., 2018). Also CMV has been associated with increased rates of psychological distress (Rector et al., 2014), depression (Gale et al., 2018), mood disorders (Burgdorf et al., 2019) and suicide (Dickerson et al., 2018). Other studies,

\footnotetext{
* Corresponding author.

E-mail address: niina.markkula@helsinki.fi (N. Markkula).
} 


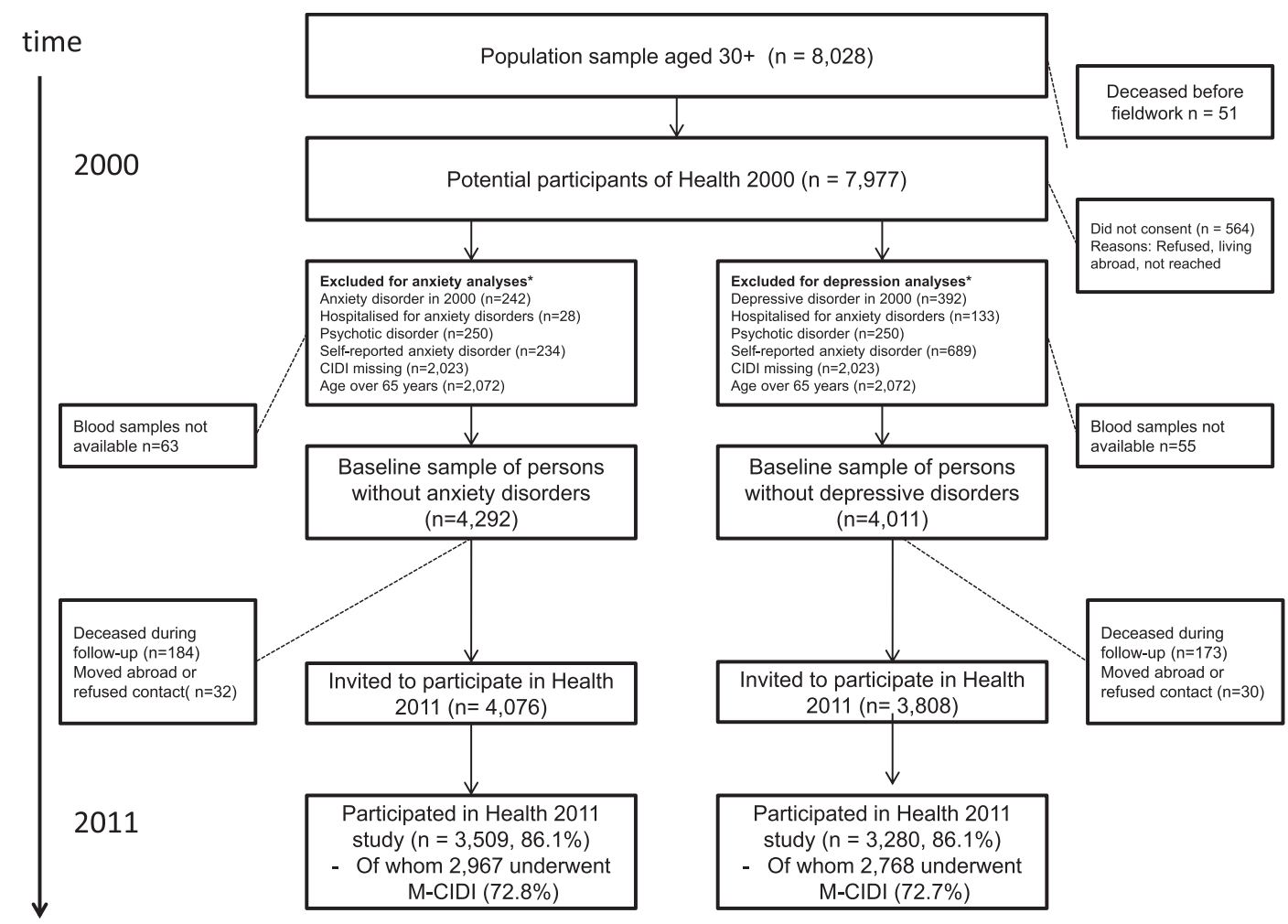

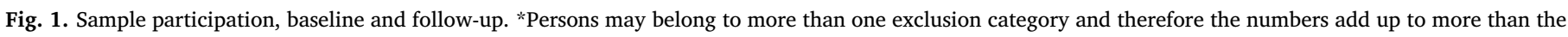
number of total exclusions.

however, have not found associations with depression (Markovitz et al., 2015; Pearce et al., 2012). One study pointed to a modification effect of gender, whereby cytomegalovirus seropositivity was associated with a lower risk of mood disorders in men, but a higher risk in women (Simanek et al., 2018a). In few prospective studies, CMV has been associated with incident depressive symptoms (Burgdorf et al., 2019; Simanek et al., 2014; Simanek et al., 2018b). CMV has also been associated with cognitive decline in the elderly (Barnes et al., 2014), although a recent Finnish study failed to find an association with cognitive decline in the adult population (Torniainen-Holm et al., 2018).

HSV-1 affects more than half of the world's population and $72 \%$ of the adult population in Finland (Torniainen-Holm et al., 2019). Its role has been studied particularly in context to cognitive decline (Piacentini et al., 2014), but HSV-1 has also been associated with depression (Lycke et al., 1974; Wang et al., 2014).

Despite an increasing interest in the role of infections in the pathogenesis of common mental disorders, very few prospective studies have been carried out to elucidate the relationship between exposure to common infectious agents and the subsequent rate of incident mood disorders. Therefore, we investigated the association of $T$. gondii, EBV, HSV-1 and CMV seropositivity and serointensity with new-onset DSM-IV anxiety and depressive disorders in an 11-year follow-up of a representative population sample. GAD was analysed separately because of several previous publications finding cross-sectional associations specifically with GAD and infections (Markovitz et al., 2015; Suvisaari et al., 2017). We also investigated whether the possible effect was mediated by inflammation, as measured by C-reactive protein (CRP) levels.

\section{Methods}

\subsection{Study sample and participants}

The Health 2000 Survey (BRIF8901), based on a nationally representative sample of 8028 adults aged 30 years and over, was conducted in 2000-2001 using a two-stage clustered sampling of 15 largest
Finnish towns and 65 health districts (Heistaro, 2008). The study protocol comprised a home interview, self-administered questionnaires and a comprehensive health examination, which included the Composite International Diagnostic Interview (CIDI). In total, 7112 persons (89\%) participated in the home interview and/or the health examination, and 6005 persons (75\%) participated in CIDI.

The Health 2011 Survey was a follow-up study of the Health 2000 Survey (Koskinen et al., 2012). All members of the Health 2000 Survey sample alive and living in Finland, unless they had refused to participate, were invited to take part. Participation in the complete Health 2011 has been reported in more detail elsewhere (Markkula et al., 2015).

In this study, the following exclusions of the study population of Health 2000 were made: To analyse risk factors for new-onset cases of depressive and anxiety disorders, for each analysis separately three groups were excluded: those with the corresponding disorder at the baseline CIDI interview (12-month diagnosis of depressive or anxiety disorder); those who reported to have been diagnosed by a doctor as suffering from a depressive or anxiety disorder during their lifetime, and those with a hospitalisation due to depressive or anxiety disorders at any point in their life prior to the baseline. For analyses of new-onset depressive disorders, depressive disorders were excluded at baseline, and similar for analyses of new-onset anxiety disorders, anxiety disorders were excluded at baseline. In addition, those with psychotic disorders at baseline were excluded from all the analyses, as the CIDI might not be an adequate method for assessing psychiatric comorbidities in people with psychotic disorders. We also excluded those who did not participate in the baseline CIDI interview, because we could not exclude baseline depression or anxiety.

Of persons older than 65 , only $59 \%$ participated in the CIDI interview at baseline, while the overall participation rate was $75 \%$. During the follow-up, $59 \%$ of persons over 65 years died. These issues may limit the generalizability of the results in this age group and therefore, the analyses in this study are limited to participants aged 30-65 years at baseline. 
Consequently, the study population at baseline consisted of 4355 persons for the anxiety disorder analyses and 4066 persons for depressive disorder analyses (Figure 1). Data on infections at baseline was available for 4011 (99\%) persons with no previous depressive disorder and $4292(99 \%)$ persons with no previous anxiety disorder.

The Health 2000 and Health 2011 studies had approval of the Ethics Committee of the Hospital District of Helsinki and Uusimaa. Participants provided written informed consent.

\subsection{Psychiatric assessment}

The Munich version of the Composite International Diagnostic Interview ( $\mathrm{M}-\mathrm{CIDI}$ ) was used to diagnose psychiatric disorders at baseline and follow-up (Andrews and Peters, 1998; Wittchen et al., 1998). The process has been described in more detail elsewhere (Markkula et al., 2015; Pirkola et al., 2005). Six disorders (panic disorder, agoraphobia, social phobia, GAD, dysthymia and major depressive disorder) during the past 12 months were assessed using diagnostic criteria of the DSM-IV. In addition, participants were inquired whether they had been diagnosed with anxiety or depression by a doctor at any point in their life, and those who reported lifetime diagnosis at baseline were excluded, as described above.

\subsection{Antibody measurements}

Plasma samples were collected from the participants in the baseline health examination. Samples were available for 6250 participants in total.

For T. gondii level measurement, the concentration of IgG antibodies was measured by solid phase enzyme immunoassay employing whole tachyzoite lysate from Ross South Labs, Spanish Fork Utah, USA (Dickerson et al., 2007). Sample values were compared to standards with known levels of antibody and converted into international units. A cut-off of $50 \mathrm{IU} / \mathrm{ml}$ was used for seropositivity. CMV, EBV and HSV IgG levels were analysed by solid-phase immunoassay using commercially available assay kits (IBL America) (Dickerson et al., 2003). Participants were rated seropositive if the optimal density value was above or at the infection point in the sample distribution. For all antibodies, also serointensity, defined as the quantitative level of antibody in terms of standardized units was used as a continuous variable.

\subsection{C-reactive protein}

To assess whether the possible association of infections and common mental disorders was mediated through low-grade infection, CRP levels were also analysed from serum samples taken at the same time as plasma samples from which the antibodies were measured. Serum high-sensitivity CRP levels (mg/L) were measured in the Health 2000 study with automated analyser (Optima, Thermo Electron Oy, Vantaa, Finland) and an immunoturbidimetric test (Ultrasensitive CRP, Orion Diagnostica, Espoo, Finland) (Heikkilä et al., 2011).

\subsection{Other variables}

We included age, sex, educational level, marital status and region of residence as possible confounding factors. Based on the baseline interview, educational level was divided into three categories according to the level of education completed: basic (no high school or vocational training), secondary (high school or completed vocational school) and higher (degree from a higher vocational institution, polytechnic or university). Marital status was categorized into married or cohabiting and other (separated, unmarried or widowed). Place of residence was categorized based on the five university hospital districts as Northern, Eastern, Western, Southwestern, and Southern Finland.

\subsection{Statistical analysis}

Age and sex standardised incidence of new-onset disorders by baseline seroprevalence was analysed and expressed in proportions with their confidence intervals (CI).

The association of seroprevalence with new-onset anxiety and depressive disorders was analysed in logistic regression models, where the outcomes were 1) new-onset depressive disorders, 2) new-onset anxiety disorders or 3) new-onset GAD. Analyses were adjusted for age, sex, educational level, marital status and region of residence. All analyses were also adjusted for the plate used in the assays to account for a platform effect in running the assays. Next, CRP level was added into the analyses. All analyses were then repeated using serointensity levels of the four types of antibodies as continuous variables.

Post hoc analyses were carried out to investigate the association of CMV and GAD separately for men and women due to earlier studies showing effect modification by gender. For this purpose, the age adjusted 12-month prevalence rates and the regression models were repeated separately for men and women.

The sampling design and varying sampling probabilities were accounted for in the analyses, and post-stratification weights were used to correct for non-response.

Stata statistical software package (version 14.2 for Mac) was used for all statistical analyses.

\section{Results}

There were 126 cases of new-onset depressive disorders and 84 cases of new-onset anxiety disorders, out of which 49 were GAD.

The age and sex standardized 12-month prevalence of new-onset depressive disorders was $4.1-4.8 \%$ across different subgroups, and did not vary significantly by seroprevalence of any infection at baseline (Table 1). Similarly, the age and sex standardized 12-month prevalence of new-onset anxiety disorders was $2.1-3.4 \%$ without significant variation by seroprevalence. The 12-month prevalence of new-onset GAD was $1.3-2.7 \%$. The prevalence was $3.1 \%$ (95\% CI 1.4-4.7) among CMV seronegative and $1.3 \%$ (95\% CI 0.8-1.7) among CMV seropositive ( $\mathrm{p}=0.009)$.

Seropositivity of any infection at baseline as a dichotomous variable, adjusted for age, sex, region of residence, education and marital status, did not increase the relative risk of new-onset depressive or anxiety disorders (Table 2). The results remained the same when serointensity, the quantitative level of antibodies, was used. Adding CRP level to the model did not change the findings. Seropositivity for CMV at baseline appeared to be protective of new-onset GAD (OR 0.43, 95\% CI $0.22-0.86)$, whereas serointensity was not $(0.88$, 95\% CI $0.76-1.03)$.

In the post hoc analyses investigating effect modification by gender in the association of CMV and GAD, the age adjusted prevalence of newonset $\mathrm{GAD}$ among CMV seronegative men was $2.6 \%$ (95\% CI 0.3-4.9) and among seropositive men $1.1 \%(95 \% \mathrm{CI} 0.4-1.7)(\mathrm{p}=0.089)$. The adjusted prevalence of new-onset GAD among CMV seronegative women was 3.5\% (95\% CI 1.2-5.8) and among seropositive women $1.5 \%(95 \%$ CI $0.8-2.1)(\mathrm{p}=0.042)$. In logistic regression, adjusted for age, education, marital status, region of residence and CRP, using CMV as a dichotomous variable (seroprevalence), OR for new-onset GAD for men was 0.46 (95\% CI $0.18-1.21)$ and for women 0.43 (95\% CI 0.18-1.03).

\section{Discussion}

In this longitudinal general population study, we did not find a positive association between antibodies for T. gondii, EBV, HSV-1 or CMV at baseline and the incidence of new-onset common mental disorders in an eleven-year follow-up. The results of this study suggest that common infections T. gondii, EBV, HSV-1 and CMV are not significant risk factors for the development of new cases of depressive or anxiety 
Table 1

12-month prevalence of new-onset depressive and anxiety disorders by T. gondii, EBV, HSV-1 and CMV seroprevalence at baseline.

\begin{tabular}{|c|c|c|c|c|c|c|}
\hline & $\begin{array}{l}\text { 12-month prevalence of } \\
\text { depressive disorders at } \\
11 \text { years' follow-up (2011), \% } \\
(95 \% \mathrm{CI})\end{array}$ & $\begin{array}{l}\text { P for } \\
\text { difference }\end{array}$ & $\begin{array}{l}\text { 12-month prevalence of anxiety } \\
\text { disorders at } 11 \text { years' follow-up } \\
(2011), \%(95 \% \mathrm{CI})\end{array}$ & $\begin{array}{l}\text { P for } \\
\text { difference }\end{array}$ & $\begin{array}{l}\text { 12-month prevalence of } \\
\text { GAD at } 11 \text { years' follow-up } \\
(2011), \%(95 \% \mathrm{CI})\end{array}$ & $\begin{array}{l}\mathrm{P} \text { for } \\
\text { difference }\end{array}$ \\
\hline \multicolumn{7}{|c|}{ T. gondii seroprevalence } \\
\hline Negative & $4.5(3.6-5.3)$ & 0.989 & $2.8(2.1-4.3)$ & 0.473 & $1.6(1.0-2.1)$ & 0.647 \\
\hline Positive & $4.2(2.6-6.3)$ & & $3.4(1.7-5.0)$ & & $1.9(0.6-3.1)$ & \\
\hline \multicolumn{7}{|c|}{ Epstein-Barr virus seroprevalence } \\
\hline Negative & $4.1(0.0-8.7)$ & 0.891 & $2.6(0.0-6.1)$ & 0.888 & $2.5(0.0-6.0)$ & 0.528 \\
\hline Positive & $4.5(3.7-5.3)$ & & $2.9(2.2-3.5)$ & & $1.6(1.1-2.1)$ & \\
\hline \multicolumn{7}{|c|}{ Herpes simplex virus 1 seroprevalence } \\
\hline Negative & $4.8(3.4-6.1)$ & 0.605 & $2.1(1.2-2.9)$ & 0.061 & $1.2(0.6-1.8)$ & 0.180 \\
\hline Positive & $4.3(3.3-5.3)$ & & $3.3(2.4-4.2)$ & & $1.9(1.1-2.7)$ & \\
\hline \multicolumn{7}{|c|}{ Cytomegalovirus seroprevalence } \\
\hline Negative & $4.4(2.7-6.2)$ & 0.940 & $3.4(1.7-5.2)$ & 0.420 & $3.1(1.4-4.7)$ & 0.009 \\
\hline Positive & $4.5(3.6-5.3)$ & & $2.7(2.0-3.4)$ & & $1.3(0.8-1.7)$ & \\
\hline
\end{tabular}

disorders in the adult population.

Considering the earlier cross-sectional associations of $T$. gondii with depressive symptoms, GAD and comorbid disorders in this study population (Suvisaari et al., 2017), and abundant literature documenting such associations in other populations (Pearce et al., 2012; Rector et al., 2014; Simanek et al., 2018b), the lack of association in this longitudinal setting was unexpected. However, our results are in line with a recent systematic review, which did not find an association between depressive disorders and T. gondii infection (Sutterland et al., 2015). Also in this study population, there was no association with current depressive disorders, only depressive symptoms and comorbid disorders (Suvisaari et al., 2017).

Previous studies have found that with increasing seroprevalence of T. gondii in the population, the more difficult it is to detect significant differences in mental health outcomes (Sutterland et al., 2015). Therefore, it is not surprising that infections with a high prevalence such as EBV (98\%) or CMV (84\%) do not appear as risk factors for common mental disorders.

One of the few other longitudinal studies on the topic assessed infections and the risk of new-onset depressive symptoms, and found that CMV, but not HSV-1, varicella zoster, T. gondii or Helicobacter pylori predicted incident depression over a nine-year follow-up (OR 1.4), and the association was not mediated by CRP or IL-6 levels (Simanek et al., $2018 b)$. In another population with a one-year follow-up, there was also an association between higher CMV, but not HSV-1, IgG antibody level and incident depressive symptoms (Simanek et al., 2014).

We found CMV seropositivity to be associated with lower risk of new-onset GAD, but not other anxiety disorders or depressive disorders.
This is in contrast with earlier literature: a recent Danish study associated CMV with risk of onset of anxiety disorders (Burgdorf et al., 2019), but did not control for socioeconomic factors. Other prospective studies have found CMV to predict incident depressive symptoms, adjusting for socioeconomic factors (Simanek et al., 2014; Simanek et al., 2018b). One previous study found the effect of CMV to differ according to gender (Simanek et al., 2018a), but this was not the case in our study population. The apparent protective effect was similar in both genders, although it lost statistical significance due to low number of observations. A similar protective effect of the CMV infection has recently been found in a study investigating the association of common infections and suicidality, but only among men (Lindgren et al., unpublished results).

It is difficult to interpret this finding, especially since this lower risk was not observed for onset of depressive or other anxiety disorders, nor when CMV serointensity was analysed. The prevalence of CMV antibodies in the Finnish population is $84 \%$. The prevalence increases with age, and is more common among women than men, and among people of lower socioeconomic status (Torniainen-Holm et al., 2018). Transmission of CMV requires contact with infectious body fluids, such as saliva, urine, blood, tears, semen or breast milk, and therefore implies intimate contact with other people (Dioverti and Razonable, 2016). It is possible that factors related to later risk of $\mathrm{GAD}$, such as social isolation or trait neuroticism (Brandes and Bienvenu, 2006), associate with lower risk of CMV through reduced contact with body fluids. However, many other viral infections have similar transmission mechanisms, and in our study the finding was specific to CMV. A direct protective effect of the infection seems unlikely.

Table 2

T. gondii, EVB, HSV-1 and CMV seropositivity and serointensity as predictors of new-onset depressive and anxiety disorders in an eleven-year follow-up of a general population*

\begin{tabular}{|c|c|c|c|c|c|c|}
\hline & \multicolumn{2}{|l|}{ Depressive disorders } & \multicolumn{2}{|l|}{ Anxiety disorders } & \multicolumn{2}{|l|}{ GAD } \\
\hline & $\begin{array}{l}\text { Seropositive } \\
\text { (dichotomous), OR } \\
(95 \% \mathrm{CI})\end{array}$ & $\begin{array}{l}\text { Serointensity } \\
\text { (continuous), OR } \\
(95 \% \mathrm{CI})\end{array}$ & $\begin{array}{l}\text { Seropositive } \\
\text { (dichotomous), OR } \\
(95 \% \mathrm{CI})\end{array}$ & $\begin{array}{l}\text { Serointensity } \\
\text { (continuous), OR } \\
(95 \% \mathrm{CI})\end{array}$ & $\begin{array}{l}\text { Seropositive } \\
\text { (dichotomous), OR } \\
(95 \% \mathrm{CI})\end{array}$ & $\begin{array}{l}\text { Serointensity } \\
\text { (continuous), OR ( } 95 \% \\
\text { CI) }\end{array}$ \\
\hline Toxoplasma gondii & $1.00(0.61-164)$ & $0.99(0.99-1.01)$ & $1.24(0.70-2.17)$ & $1.00(0.99-1.01)$ & $1.17(0.55-2.46)$ & $1.00(0.99-1.01)$ \\
\hline Adjusted for CRP & $1.00(0.61-1.64)$ & $0.99(0.99-1.01)$ & $1.23(0.70-2.15)$ & $1.00(0.99-1.01)$ & $1.16(0.55-2.43)$ & $1.00(0.99-1.01)$ \\
\hline Epstein-Barr virus & $1.09(0.33-3.60)$ & $1.05(0.76-1.44)$ & $1.10(0.27-4.46)$ & $1.03(0.67-1.60)$ & $0.66(0.17-2.62)$ & $0.86(0.48-1.56)$ \\
\hline Adjusted for CRP & $1.09(0.33-3.60)$ & $1.05(0.76-1.44)$ & $1.11(0.27-4.49)$ & $1.05(0.68-1.61)$ & $0.66(0.17-2.63)$ & $0.87(0.48-1.56)$ \\
\hline $\begin{array}{l}\text { Herpes simplex virus } \\
\quad 1\end{array}$ & $0.88(0.59-1.31)$ & $0.97(0.90-1.06)$ & $1.60(0.95-2.68)$ & $1.03(0.94-1.12)$ & $1.73(0.89-3.40)$ & $1.04(0.93-1.17)$ \\
\hline Adjusted for CRP & $0.88(0.59-1.31)$ & $0.97(0.90-1.06)$ & $1.61(0.96-2.70)$ & $1.03(0.94-1.13)$ & $1.74(0.89-3.42)$ & $1.04(0.93-1.17)$ \\
\hline Cytomegalovirus & $1.05(0.65-1.68)$ & $1.04(0.95-1.15)$ & $0.79(0.44-1.42)$ & $1.02(0.90-1.14)$ & $0.43(0.22-0.85)$ & $0.87(0.77-1.03)$ \\
\hline Adjusted for CRP & $1.05(0.65-1.68)$ & $1.04(0.95-1.15)$ & $0.79(0.44-1.42)$ & $1.01(0.90-1.14)$ & $0.43(0.22-0.86)$ & $0.88(0.76-1.03)$ \\
\hline
\end{tabular}

*All analyses adjusted for age, sex, education, marital status and region of residence. 


\section{Strengths and limitations}

The main strengths of this study are the representative population sample, large sample size and reliable psychometric procedures used. Unfortunately, we did not have information on psychiatric disorders between the two measurement points, and therefore may have missed new cases that had occurred and remitted during the follow-up. We also did not have new antibody assessments at follow-up, and therefore we could not assess seroconversion and the impact of newly acquired infections. IgM antibodies indicating acute infection were not available for analysis.

It is also worth noting that the study population was 30-65 years old at baseline and 41-76 years at the follow-up. If the effect of infections is age-dependent, the lack of adolescents and young adults in the study population is a limitation. Another factor worth noting is that the seroprevalence of herpesviruses has decreased in Finland in recent decades (Puhakka et al., 2016). The reason for this is unknown and could cause residual confounding, although we did adjust for both age and other sociodemographic factors in the analyses.

\section{Conclusions}

The results of this large, nationally representative longitudinal study suggest that common viral infections are not significant risk factors for common mental disorders. The association of CMV with apparent better mental health warrants further investigation.

\section{Funding}

This work was supported by Stanley Medical Research Institute, Juho Vainio Foundation (ML), Yrjö Jahnsson Foundation (ML, grant number 6979) and Helsinki University Competitive Research Funding (NM). The funding sources had no role in the study design, in the collection, analysis and interpretation of data, in the writing of the report, or the decision to submit the article for publication.

\section{Appendix A. Supplementary data}

Supplementary data to this article can be found online at https:// doi.org/10.1016/j.bbi.2019.12.001.

\section{References}

Andrews, G., Peters, L., 1998. The psychometric properties of the Composite International Diagnostic Interview. Soc Psychiatry Psychiatr Epidemiol 33, 80-88.

Barnes, L.L., Capuano, A.W., Aiello, A.E., Turner, A.D., Yolken, R.H., Torrey, E.F., Bennett, D.A., 2014. Cytomegalovirus Infection and Risk of Alzheimer Disease in Older Black and White Individuals. J. Infect. Dis. 211, 230-237.

Benros, M.E., Waltoft, B.L., Nordentoft, M., et al., 2013. Autoimmune diseases and severe infections as risk factors for mood disorders: A nationwide study. JAMA Psychiatry 70, 812-820.

Brandes, M., Bienvenu, O.J., 2006. Personality and anxiety disorders. Current Psychiatry Reports 8, 263-269.

Burgdorf, K.S., Trabjerg, B.B., Pedersen, M.G., Nissen, J., Banasik, K., Pedersen, O.B., Sorensen, E., Nielsen, K.R., Larsen, M.H., Erikstrup, C., Bruun-Rasmussen, P., Westergaard, D., Thorner, L.W., Hjalgrim, H., Paarup, H.M., Brunak, S., Pedersen, C.B., Torrey, E.F., Werge, T., Mortensen, P.B., Yolken, R.H., Ullum, H., 2019. Largescale study of Toxoplasma and Cytomegalovirus shows an association between infection and serious psychiatric disorders. Brain Behav Immun.

Coughlin, S.S., 2012. Anxiety and Depression: Linkages with Viral Diseases. Public health reviews 34

Dantzer, R., O'Connor, J.C., Freund, G.G., Johnson, R.W., Kelley, K.W., 2008. From inflammation to sickness and depression: when the immune system subjugates the brain. Nat. Rev. Neurosci. 9, 46-56.

Dickerson, F., Boronow, J., Stallings, C., Origoni, A., Yolken, R., 2007. Toxoplasma gondii in individuals with schizophrenia: Association with clinical and demographic factors and with mortality. Schizophr. Bull. 33, 737-740.

Dickerson, F., Origoni, A., Schweinfurth, L.A.B., Stallings, C., Savage, C.L.G., Sweeney, K., Katsafanas, E., Wilcox, H.C., Khushalani, S., Yolken, R., 2018. Clinical and Serological Predictors of Suicide in Schizophrenia and Major Mood Disorders. J.
Nerv. Ment. Dis. 206, 173-178.

Dickerson, F., Wilcox, H.C., Adamos, M., Katsafanas, E., Khushalani, S., Origoni, A., Savage, C., Schweinfurth, L., Stallings, C., Sweeney, K., Yolken, R., 2017. Suicide attempts and markers of immune response in individuals with serious mental illness. J. Psychiatr. Res. 87, 37-43.

Dickerson, F.B., Boronow, J.J., Stallings, C., Origoni, A.E., Ruslanova, I., Yolken, R.H., 2003. Association of serum antibodies to herpes simplex virus 1 with cognitive deficits in individuals with schizophrenia. Arch. Gen. Psychiatry 60, 466-472.

Dioverti, M.V., Razonable, R.R., 2016. Cytomegalovirus. Microbiology Spectrum 4.

Gale, S.D., Berrett, A.N., Erickson, L.D., Brown, B.L., Hedges, D.W., 2018. Association between virus exposure and depression in US adults. Psychiatry Res. 261, 73-79.

Heikkilä, K., Silander, K., Salomaa, V., Jousilahti, P., Koskinen, S., Pukkala, E., Perola, M., 2011. C-reactive protein-associated genetic variants and cancer risk: Findings from FINRISK 1992, FINRISK 1997 and Health 2000 studies. Eur. J. Cancer 47, 404-412.

Heistaro, S.e., 2008. Methodology Report. Health 2000 survey. In: Institute, N.P.H. (Ed.), Publications of the National Public Health Institute, KTL. National Public Health Institute, Helsinki, p. 248

Koskinen, S., Lundqvist, A., Ristiluoma, N., 2012. Terveys, toimintakyky ja hyvinvointi Suomessa 2011. Terveyden ja hyvinvoinnin laitos, Tampere.

Lindgren, M., Torniainen-Holm, M., Härkänen, T., Dickerson, F., Yolken, R.H., Suvisaari, J., 2018. The association between toxoplasma and the psychosis continuum in a general population setting. Schizophr. Res. 193, 329-335.

Lycke, E., Norrby, R., Roos, B.E., 1974. A serological study on mentally ill patients with particular reference to the prevalence of herpes virus infections. The British journal of psychiatry : the journal of mental science 124, 273-279.

Markkula, N., Suvisaari, J., Saarni, S.I., Pirkola, S., Pena, S., Saarni, S., Ahola, K., Mattila, A.K., Viertio, S., Strehle, J., Koskinen, S., Härkänen, T., 2015. Prevalence and correlates of major depressive disorder and dysthymia in an eleven-year follow-up-results from the Finnish Health 2011 Survey. J Affect Disord 173, 73-80.

Markovitz, A.A., Simanek, A.M., Yolken, R.H., Galea, S., Koenen, K.C., Chen, S., Aiello, A.E., 2015. Toxoplasma gondii and anxiety disorders in a community-based sample. Brain Behav. Immun. 43, 192-197.

Nayeri Chegeni, T., Sharif, M., Sarvi, S., Moosazadeh, M., Montazeri, M., Aghayan, S.A., Balalami, N.J., Gholami, S., Hosseininejad, Z., Saberi, R., Anvari, D., Gohardehi, S., Daryani, A., 2019. Is there any association between Toxoplasma gondii infection and depression? A systematic review and meta-analysis. PLOS ONE 14, e0218524.

Pearce, B.D., Kruszon-Moran, D., Jones, J.L., 2012. The relationship between Toxoplasma gondii infection and mood disorders in the third National Health and Nutrition Survey. Biol. Psychiatry 72, 290-295.

Piacentini, R., De Chiara, G., Li Puma, D.D., Ripoli, C., Marcocci, M.E., Garaci, E., Palamara, A.T., Grassi, C., 2014. HSV-1 and Alzheimer's disease: more than a hypothesis. Frontiers in Pharmacology 5.

Pirkola, S.P., Isometsä, E., Suvisaari, J., Aro, H., Joukamaa, M., Poikolainen, K., Koskinen, S., Aromaa, A., Lönnqvist, J.K., 2005. DSM-IV mood-, anxiety- and alcohol use disorders and their comorbidity in the Finnish general population-results from the Health 2000 Study. Soc Psychiatry Psychiatr Epidemiol 40, 1-10.

Puhakka, L., Sarvikivi, E., Lappalainen, M., Surcel, H.M., Saxen, H., 2016. Decrease in seroprevalence for herpesviruses among pregnant women in Finland: cross-sectional study of three time points 1992, 2002 and 2012. Infectious diseases (London, England) 48, 406-410.

Rector, J.L., Dowd, J.B., Loerbroks, A., Burns, V.E., Moss, P.A., Jarczok, M.N., Stalder, T, Hoffman, K., Fischer, J.E., Bosch, J.A., 2014. Consistent associations between measures of psychological stress and CMV antibody levels in a large occupational sample. Brain Behav Immun 38, 133-141.

Saadatnia, G., Golkar, M., 2012. A review on human toxoplasmosis. Scand. J. Infect. Dis. 44, 805-814.

Simanek, A.M., Cheng, C., Yolken, R., Uddin, M., Galea, S., Aiello, A.E., 2014. Herpesviruses, inflammatory markers and incident depression in a longitudinal study of Detroit residents. Psychoneuroendocrinology 50, 139-148.

Simanek, A.M., Parry, A., Dowd, J.B., 2018a. Differences in the association between persistent pathogens and mood disorders among young- to middle-aged women and men in the U.S. Brain Behav Immun 68, 56-65.

Simanek, A.M., Zheng, C., Yolken, R., Haan, M., Aiello, A.E., 2018b. A Longitudinal Study of the Association Between Persistent Pathogens and Incident Depression Among Older US Latinos. The journals of gerontology. Series A, Biological sciences and medical sciences.

Sutterland, A.L., Fond, G., Kuin, A., Koeter, M.W.J., Lutter, R., Gool, T., Yolken, R., Szoke, A., Leboyer, M., Haan, L., 2015. Beyond the association. Toxoplasma gondii in schizophrenia, bipolar disorder, and addiction: systematic review and meta-analysis. Acta Psychiatr. Scand. 132, 161-179.

Suvisaari, J., Torniainen-Holm, M., Lindgren, M., Härkänen, T., Yolken, R.H., 2017. Toxoplasma gondii infection and common mental disorders in the Finnish general population. J. Affect. Disord. 223, 20-25.

Torniainen-Holm, M., Suvisaari, J., Lindgren, M., Harkanen, T., Dickerson, F., Yolken, R.H., 2019. The lack of association between herpes simplex virus 1 or Toxoplasma gondii infection and cognitive decline in the general population: An 11-year followup study. Brain Behav Immun 76, 159-164.

Torniainen-Holm, M., Suvisaari, J., Lindgren, M., Härkänen, T., Dickerson, F., Yolken, R.H., 2018. Association of cytomegalovirus and Epstein-Barr virus with cognitive functioning and risk of dementia in the general population: 11-year follow-up study. Brain Behav. Immun. 69, 480-485.

Wang, X., Zhang, L., Lei, Y., Liu, X., Zhou, X., Liu, Y., Wang, M., Yang, L., Zhang, L., Fan, S., Xie, P., 2014. Meta-analysis of infectious agents and depression. Sci. Rep. 4, 4530.

Wittchen, H.U., Lachner, G., Wunderlich, U., Pfister, H., 1998. Test-retest reliability of the computerized DSM-IV version of the Munich-Composite International Diagnostic Interview (M-CIDI). Soc Psychiatry Psychiatr Epidemiol 33, 568-578. 